\title{
What relations are: A case study on conceptual relations, displacement of meaning and knowledge profiling
}

\author{
Torkild Thellefsen, Christian Jantzen \\ Department of Communication, Aalborg University \\ Kroghstræde 3, 9220 Aalborg, Denmark \\ e-mail: tlt@hum.auc.dk; jantzen@hum.auc.dk
}

\begin{abstract}
The aim of the article is to introduce the knowledge profile as a tool to make realistic representations of knowledge organizations. In order to make these realistic representations, we must identify the fundamental sign of the given knowledge domains, since it seems to be the case that the fundamental sign puts epistemological constraints upon its research objects, eventually making the knowledge organization of a knowledge domain unique. Furthermore, the article points out that in order to make the realistic representations of knowledge organizations, we need a basic understanding of how conceptual relations emerge, develop and become related terms. In order to strengthen the theoretical points and to show the usability of the knowledge profile, we include a case study of a knowledge domain.
\end{abstract}

Pragmaticism consists in holding that the purport of any concept is its conceived bearing upon our conduct.

C. S. Peirce (CP 5.442)

\section{Introduction}

In the literature on Library and Information Science (LIS), ${ }^{1}$ we often encounter the concept "related term" as an entity that needs no further

\footnotetext{
1 We use LIS as an example of a research field that uses a well-developed classification of relations. Naturally, there are other research fields, which also have developed such classification. However, being a librarian (Thellefsen) LIS seems obvious to use as an example.
} 
definition and as something that is obvious. However, if we submit the concept to further exploration, the lack of preciseness makes the definition and classification of related terms somewhat confusing. In the literature on thesaurus construction, ${ }^{2}$ relations are classified in the following way: broader term (BT) defined as a superordinate term in a hierarchical relation; narrower term (NT) defined as a narrower term to the heading term; related term (RT) defined as a term in a semantic relation, but not in a hierarchical relation, to another term; semantic relation (SR) defined as a relation between terms that is true as a matter of general knowledge, rather than depending on what the terms refer to in some particular document.

Of course, this is only a small excerpt of the general classification of terms in the study of thesaurus construction. However, we believe that the terms mentioned here emphasize one of the basic problems in LIS, namely the lack of ability to provide an answer to the most basic and simple question: regarding the nature of a related term - or to put it more simply: What is a related term?

When looking at the classification of related terms cited from LIS, there seems to be a need to operate with different types of relations. It is unclear; however, what makes a term more or less broad. Moreover, are NTs or SRs not related terms as a related term has it own name RT? Furthermore, the classification is unable to explain how relations emerge and how they are identified. How do we, e.g., determine that the term activity dysfunction within the knowledge domain of Occupational Therapy is related to activity? The answer could be based on the obvious similarity between the words. However, the case is considerably more complicated when the question addresses $A$-one as a related term to activity. Our answer to these questions is: a related term is a term that shares epistemological qualities with the concept to which it relates. This means that the epistemological qualities of the concept are displaced to the related term, hence we get a displacement of meaning and the relation is maintained by an interpretative habit of conduct.

This answer leads to even more questions: What is an epistemological quality and how do we identify these epistemological qualities; and are concepts able to carry such qualities in the first place? Furthermore, what is a habit of conduct? Are we able to identify such a habit?

2 See http://instruct.uwo.ca/gplis/677/thesaur/main00.htm for a thorough definition of how to construct a thesaurus. 
These questions imply a more theoretical understanding of concepts and related terms. We believe that it is crucial to ask these kinds of questions since the answers provide new and, in our opinion, better ways to create representations of knowledge organisations.

Before we address the questions, we make a digression to Peirce's doctrine of pragmaticism since this doctrine is able to provide the theoretical background for the answers to the above questions. We will not deal with pragmaticism in detail. Instead, we will define basic concepts from pragmaticism, which have an important impact upon concepts and related terms. Furthermore, we will introduce a new method of making representations of knowledge organisations: the knowledge profile (Thellefsen 2003b; 2004b). The knowledge profile consists of three elements: the epistemological basis, the consequences of this epistemological basis, and a knowledge map (Thellefsen 2003a; 2004a).

The epistemological basis is the knowledge basis of a particular knowledge domain. It contains the goal(s) and epistemological qualities (in a knowledge management context, epistemological qualities could also be called values) of the knowledge domain.

The consequences of the epistemological basis are the meaning of the epistemological basis. The consequences are manifestations of the epistemological basis. It is the sum of consequences that lead us towards the full understanding of the epistemological basis.

Knowledge profiling as a research area is also a matter of sharpening the terminology of a research area. The identification of the epistemological basis is a process of sharpening terminology - an identification and construction of a given conceptual order. The most precise state of the epistemological basis, where most of the disturbing connotations have been removed and its most precise consequences are identified is the fundamental $\operatorname{sign}^{3}$ of the particular research area.

The knowledge map depicts the knowledge organization of a particular knowledge domain. It shows how the related terms are organized in relation to the fundamental sign of the knowledge domain. The knowledge map differs from other classifications of relations since the terms are organized according to the socio-cognitive knowledge structures of the actors in the knowledge domain. When drawing the knowledge map, we do not engage any relation classifications such as: superordinate or subordinate levels or any other concept hierarchies.

3 The fundamental sign is developed in Thellefsen $(2002 ; 2003 b)$. 
These classifications seem to be artificial concept constructions that are unrealistic when it comes to mapping the knowledge structures of a research area. ${ }^{4}$

Summing up, knowledge profiling has the following aim: to identify the epistemological qualities of a research area such as: a concept, a research project, a knowledge domain, a corporation, etc. and thus to identify the habits of conduct within a particular field of research in order to: (1) sharpen the given terminology of the particular research field; (2) identify the fundamental sign of a particular research field; (3) draw a knowledge map of the particular research field.

These points are important since it is the habit of conduct that makes the relation between a concept and a related term possible. Basically, we need the knowledge profile in order to answer the questions stated above. In order to demonstrate the theoretical points, we present the complete knowledge profile and structure of concepts for the knowledge domain MARKK ${ }^{5}$.

MARKK is a research unit within Market Communication and Aesthetics at Aalborg University. It was founded in 2002 by a group of four senior researchers who have been working within this field in various more or less formalised groupings for at least a decade. The reason for establishing MARKK was primarily to create a permanent organisation for developing the knowledge domain. Secondly, the intention was to integrate junior researchers and $\mathrm{PhD}$-students into more formal research programmes. The wish to create a platform for external funding was a third reason for this initiative. Today, MARKK consists of 10 members and offers frequent seminars on research topics. As a research unit, MARKK focuses on aesthetic aspects of Market Communication in order to: (a) examine the aesthetic potentials of the formal features of Market Communication; (b) investigate the impact of aesthetics on cognition in the moment of exposure, (c) understand by which means and in which ways Market Communications has a bearing on culture (and cultural change), e.g. on influencing the ideas and values of the consumer or on shaping concrete forms of practice (habits, rituals, etc.).

\footnotetext{
4 This does not mean that we disapprove of the mentioned concept hierarchical structures. We simply mean that they come into play in a later stage of knowledge organization.

5 MARKK is an abbreviation for (Market communication, Aesthetics, Reception, $\mathbf{K}(\mathrm{C})$ ognition, and $\mathbf{K}(\mathrm{C}) \mathrm{ultur})$.
} 
As an acronym, MARKK stands for "Market communication and Aesthetics: Reception (exposure), Cognition and Culture". However, before we start defining the knowledge profile, let us take a closer look at the doctrine of pragmaticism.

\section{Pragmaticism}

Peirce's doctrine of pragmaticism is central to the understanding of knowledge and knowledge organisation. Indeed, Peirce defines the meaning of a concept to be the sum of its conceivable consequences. "Pragmaticism consists in holding that the purport of any concept is its conceived bearing upon our conduct" (CP 5.442). And further: "[...] pragmatism does not undertake to say in what the meanings of all signs consist, but merely to lay down a method of determining the meanings of intellectual concepts, that is, of those upon which reasonings may turn" (CP 5.8). Furthermore, Peirce writes: "Now pragmaticism is simply the doctrine that the inductive method is the only essential to the ascertainment of the intellectual purport of any symbol" (CP 8.209). In other words, pragmaticism deals with identifying the meaning of symbols by examining the consequences of symbols. If we translate symbols ${ }^{6}$ to concepts within a knowledge domain, and we have to accept that the knowledge domain places interpretive constraints upon its concepts, we arrive at the following definition: within a knowledge domain, the meaning of a concept is identifiable in its related terms.

Let us elaborate upon this. How does a consequence become a related term? This can be accounted for by the following interpretive steps.

1. We understand bearing (from the quote) as consequences.

2. Tested consequences are general relations hence the general relations of a concept are related terms and only general relations can be related terms.

3. Since any interpretation of a concept is a consequence and can express personal whims and preferences among the users, the consequence have to be tested within the knowledge domain.

6 Indeed, a concept is a symbol or a network of symbols. 
4. A test is simply whether or not the term finds footing and is used according to the methods to obtain knowledge in the knowledge domain.

5. If so, the knowledge it contains is generalised and has been found useful; if it does not find footing, it may wither away.

Summing up, a related term is a consequence that has been tested through the use and experience of members in a knowledge domain and not all consequences become related terms.

Based on this very short pragmaticistically inspired definition of the meaning of concepts, we gain a very useful idea of the relation between a concept and its related terms. However, in order to answer the questions posed in the beginning of the article, we have to take a closer look at the epistemology that lies within the doctrine of pragmaticism. However, we will not deal with all the aspects of pragmaticism. The aspects that lie within the doctrine of fallibilism and the metaphysical realism will be sufficient to provide the epistemological background for satisfactory answers to the question of relations.

\section{The fallibilistic and realistic angle of knowledge}

The doctrine of Fallibilism is the idea that knowledge is provisory. This means that knowledge is not static but develops as its meaning grows and, as Peirce writes, symbols tend to grow as a response to the usage of the symbols (CP 2.302). This growth of meaning also applies to concepts within knowledge domains. However, the growth of a concept resides in its conceivable consequences, which means that the development of a concept resides in the future. Consequently, the meaning of a concept cannot be static since we have not learned the consequences of the given concept. Peirce defines the doctrine of fallibilism in the following quotations.

Thus, the universe is not a mere mechanical result of the operation of blind law. The most obvious of all its characters cannot be so explained. It is the multitudinous facts of all experience that show us this; but that which has opened our eyes to these facts is the principle of fallibilism. Those who fail to appreciate the importance of fallibilism reason: we see these laws of mechanics; we see how extremely closely they have been verified in some cases. We suppose that what we haven't examined is like what we have examined, and that these laws are absolute, and the whole universe is a boundless machine working by the blind laws of mechanics. This is a 
philosophy which leaves no room for a God! No, indeed! It leaves even human consciousness, which cannot well be denied to exist, as a perfectly idle and functionless flaneur in the world, with no possible influence upon anything - not even upon itself. Now will you tell me that this fallibilism amounts to nothing? (CP 1.162-163)

Even though this quotation has a cosmological turn, it emphasises the nature of fallibilism in a very precise way. We simply cannot suppose the exactitude of what we have not examined based on what we have examined. In knowledge organization, this means that we cannot just presuppose a concept relation without prior investigation just because similar cases indeed turned out to be relations. In the following quotation, Peirce defines the doctrine of fallibilism in the context of proportions.

All positive reasoning is of the nature of judging the proportion of something in a whole collection by the proportion found in a sample. Accordingly, there are three things to which we can never hope to attain by reasoning, namely, absolute certainty, absolute exactitude, absolute universality. We cannot be absolutely certain that our conclusions are even approximately true; for the sample may be utterly unlike the unsampled part of the collection. We cannot pretend to be even probably exact; because the sample consists of but a finite number of instances and only admits special values of the proportion sought. Finally, even if we could ascertain with absolute certainty and exactness that the ratio of sinful men to all men was as 1 to 1 ; still among the infinite generations of men there would be room for any finite number of sinless men without violating the proportion. The case is the same with a seven legged calf. Now if exactitude, certitude, and universality are not to be attained by reasoning, there is certainly no other means by which they can be reached. (CP 1.141-142)

Basically, Peirce states the same here as in the previous quotation; our senses are fallible thus our reasoning is fallible and based on the fact that every proportion we make can only be approximately true. Of course, this is the case when dealing with knowledge organisation. A representation of a knowledge domain e.g. a knowledge profile, a thesaurus, or a classification scheme is only approximate. When we accept this, we must do our outmost to make realistic representations that are as close as possible to the object represented. Here, we argue that we have to use the knowledge profile as the foundation for making realistic or approximately true representations. A thesaurus or a classification scheme that is constructed without this thorough preliminary work will be unrealistic or simply wrong. We will conclude 
this line of quotes with another quote that sums up the fallibilistic impact upon knowledge:

By his system of nomenclature, Sir William Hamilton has conferred an immense boon not alone on his own school but on all English philosophers who believe in anchoring words to fixed meanings. I deeply regret that I am not one of these. That is the best way to be stationary, no doubt. But, nevertheless, I believe in mooring our words by certain applications and letting them change their meaning as our conceptions of the things to which we have applied them progresses. (Peirce, Writings 1: 58) ${ }^{7}$

Hence, the essence of fallibilism is that the meaning of a concept grows concurrently with the amount of the consequences we learn from the concept. In some way, we have to deal with the progressive nature of knowledge. Universalistic knowledge theories certainly cannot grasp the growth of concepts if our aim is to make realistic representations of knowledge organisations.

However, fallibilism is not the only aspect of Peirce's doctrine of pragmaticism that has an impact upon our understanding of concepts. As the researcher Eugene Halton writes: "Though largely of a conventional nature, language is a mode of conduct, and as such, produces conceivable consequences and is normatively bounded. In its abilities to body forth new possibilities for conduct, to determine and be determined by further experience, and to communicate valid generals bearing conceivable consequences, language is real". ${ }^{8}$ Peirce writes: "But if he thinks that, whether the word 'hard' itself be real or not, the property, the character, the predicate, hardness, is not invented by men, as the word is, but is really and truly in the hard things and is one in them all, as a description of habit, disposition, or behavior, then he is a realist" (CP 1.27 Cross-Ref).

So, it is not the word as such that is real, it is the qualities carried by the word and the habits of conduct making the word mean what it means that make the word real. And it is the qualities that are interesting when dealing with relations, because it is the qualities of the concept that become displaced to the related term. Indeed, it is the qualities and the interpretative habits we are able to identify. We will return to this important point when defining the knowledge profile. According to Peirce, a concept is a general and a manifested general is

Cf. http://members.door.net/arisbe/.

8 From http://www.nd.edu/ ehalton/Peirce.htm. 
a real (CP 5.430). The general concept is an abstract and real entity, and the real is a manifestation of the general concept - it is a relation. The researcher C. Hausman describes Peirce's view on generals in the following way:

Peirce's conception of generals as reals was not, as indicated earlier, a commitment to the reality of universals in the sense in which universals are construed as static, completely determinate identities. For Peirce, generals are dynamic; they are tendencies that grow. A general should not be thought of apart from a telos. With respect to being a habit, a third or general is what it is by virtue of its influence on its future instances. A general is developmental, leading toward a more and more determinate realization of what had been unrealized. Generals can grow - first, individually, by changing identity or by being modified as rules can be modified, and, second, as complexes of intelligible identities or rules that contribute their intelligibilities to an evolving system of generals. (Hausman 1992: 12)

The main points from this quote are: (1) generals are dynamic; (2) generals are habits of conduct; (3) generals have a tendency to grow; (4) generals have a telos; (5) generals develop hitherto unrealised aspects.

If we take a closer look at the first point "generals are dynamic", and try to elaborate upon it, we will see that this point implies all the following points. How can an abstract entity be dynamic? To answer this question, we have to understand Peirce's definition of an idea:

Three elements go to make up an idea. The first is its intrinsic quality as a feeling. The second is the energy with which it affects other ideas, an energy which is infinite in the here-and-nowness of immediate sensation, finite and relative in the recency of the past. The third element is the tendency of an idea to bring along other ideas with it. (CP 1.135)

However, the definition of the idea concerns the creation of an individual idea that starts to grow. The development of the individual idea into a symbol is what Hausman means when he interprets Peirce by writing: "[...] generals can grow - first, individually, by changing identity or by being modified as rules can be modified" (Hausman 1992: 12). However, the nature of the individual general makes it search for "[...] complexes of intelligible identities or rules that contribute their intelligibilities to an evolving system of generals" (Hausman 1992: 12). This must be what Peirce means, when he writes: "Symbols grow [...] a symbol, once in being, spreads among 
the peoples. In use and in experience, its meaning grows" (CP 2.302). Consequently, a general is a symbol or a complex of symbols constrained by certain conditions.

However, we still need to account for the determination of generals and more specifically generals as concepts in language of special purposes (LSP). Symbols grow through use and experience; concepts within knowledge domains also grow through use and experience. In fact, concepts are formed by the use and experience of the actors within the knowledge domain. The growth of concept meaning is determined by the conditions of the knowledge domain in question. This not only makes concepts able to grow in meaning but also to match the knowledge need in a knowledge domain. We may think of concepts as a kind of knowledge plasticity shaped in accordance with the way in which we form concepts. This constructs the telos of concepts and the form of the concepts is based upon a habit of conduct - namely the habit based upon the epistemological basis of the knowledge domain. Indeed, it is within the epistemological basis that we can identify the basic interpretative habit and its epistemological qualities. The epistemological basis can be understood as the sum of epistemological choices made in the knowledge domain, or as the ontology of the knowledge domain. The interpretative habit is similar to the fundamental sign (Thellefsen 2002; 2003). We will return to the epistemological basis and the fundamental sign when defining the knowledge profile.

In summary, we are dealing with a kind of constructivism - a pragmaticistic constructivism. The meaning of concepts is constructed, i.e. formed and sharpened by the use and experience of the actors in a knowledge domain. However, this constructivism is based on a realism that is best described as a metaphysical realism. Therefore, the meaning of concepts refers to generals that exist independently of human minds. Manifested reals within a knowledge domain are signs that refer to a dominating interpretative habit. The qualities and the dominating habit are identifiable in the conceptual structures of a knowledge domain. We will return to the definition of pragmaticistic constructivism after having defined and discussed the concept of sign displacement (displacement of meaning) and the knowledge profile. 


\section{The knowledge profile}

As we stated in the introduction, the knowledge profile is a way to create realistic representations of knowledge organisations. We claim that these representations are more in accordance with the way researchers within a specific knowledge domain actually structure their knowledge. Our claim is based on two presumptions:

(1) we believe that knowledge structures are socio-cognitive: meaning within a knowledge domain is created through the interactions of the actors in this domain;

(2) we believe that the knowledge organisation of a knowledge domain is unique to that specific domain.

Knowledge profiling is thus a reconstruction of the unique sociocognitive structures in a specific knowledge domain. In order to make realistic representations of the knowledge organisations within knowledge domains this means that we must be in accordance with the knowledge domain in question. If, as information specialists, we neglect the uniqueness of every knowledge domain, we commit the error of making representations of knowledge organizations that fit perfectly into the world of e.g. Library Science but do not represent the internal organisation of the knowledge domain in question. ${ }^{9}$

As argumentation, we will further define the knowledge profile and provide an example of its usability as a tool to investigate the socio-cognitive structures of a specific knowledge domain. The knowledge profile consists of three basic elements: the epistemological basis, the consequences of this epistemological basis and a knowledge map. The idea of the epistemological basis is based on the pragmaticistic idea that every choice has consequences. This also applies for science. Every choice that affects the research object has consequences for this object. If terminology studies are conducted within the framework of pragmaticism, we have to follow the basic epistemological ideas of pragmaticism. We cannot neglect the aspect of fallibilism or the metaphysical realism, or the objective idealism for that matter. These -isms are essential to pragmaticism. If we ignore them, we are guilty of unethical terminological behaviour. We ought to have very important reasons and very good arguments for neglecting this epistemological basis of the doctrine of pragmaticism.

\footnotetext{
9 Unfortunately, this is the case with most information retrieval systems and
} thesauri. 
Let us take a closer look at the first part of the knowledge profile: the epistemological basis.

\section{The epistemological basis}

The epistemological basis is the sum of theoretical choices used to e.g. solve a given problem or analyse a given research object. The epistemological basis is the qualities of the concept that are shared between the concept and its related term. It is the way in which the knowledge domain has historically chosen to view and understand its particular research object. In the following, we will use the knowledge domain of "MARKK" as an example of how to draw up a knowledge profile.

\section{Epistemological basis}

\section{Consequences}

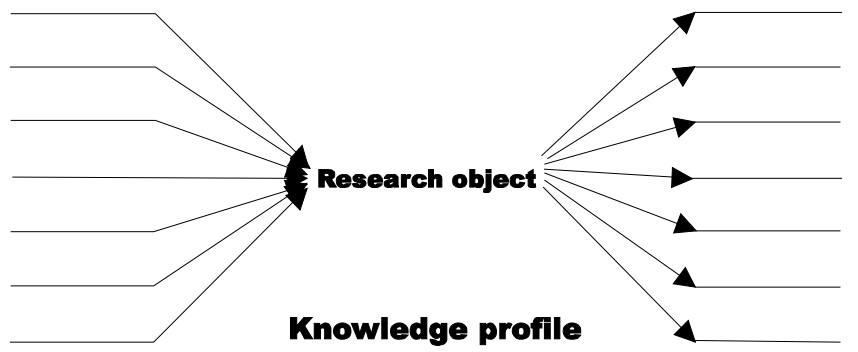

Figure 1. How to draw a knowledge profile.

We use the Figure 1 and the following six-step method:

1. Draw the knowledge profile of your concept, your project or your knowledge domain by identifying its epistemological basis and the consequences of this epistemological basis.

2. Start by writing the name of the research object (see Fig. 1), the concept, the problem, the knowledge domain in the middle. In the case of MARKK, we write MARKK in the middle.

3. Consider what theoretical basis you will unfold upon the research object; identify the most general state. Place the most general state 
of theory on the first line in the upper left side of Fig. 1. In the case of MARKK, this is Aesthetics.

4. Consider how to sharpen this general mode by prefixing or suffixing terms to the concept. Peirce did this to positivism, which he prefixed with prope, and defined his pragmaticism as propepositivism (CP 5.412). See point 2 below.

5. Consider whether you can sharpen the concept/phrase even further e.g. by using a theory within the theory that narrows down the knowledge potential of the concept or use another theory that can make your concept or project more precise See point 3 below.

6. Consider whether you need to sharpen your concept even further, or whether you are ready to identify the consequences of your concept. See point 4, 5, and 6 below.

Working on the knowledge profile of MARKK, we have identified this epistemological basis (of MARKK):

1. Aesthetics

2. Aesthetics in Market Communication

3. Formal aspects of Aesthetics in Market Communication

4. Formal aspects of Aesthetics in Market Communication from a structuralistic perspective

5. Formal aspects of Aesthetics in Market Communication from a structuralistic perspective with focus on the process of signification in the moment of exposure

6. Formal aspects of Aesthetics in Market Communication from a structuralistic perspective with focus on the process of signification, understood as the intertwining of cognition and culture, in the moment of exposure

The point of departure in MARKK is not Market Communication but Aesthetics, which defines MARKK as a humanistic approach and not a marketing approach. This is step 1, a crucial one because it is seminal for the ideas, methodologies and other ways of practising research (organising and presenting knowledge) in MARKK. But in step 2, it is stated that MARKK is about aesthetics in a specific field (Market Communication). So, it is neither about the philosophy of aesthetics nor about art, nor media aesthetics in general. MARKK is solely interested in aesthetics that serve market communicative purposes: to convince consumers/receivers of the necessity of a certain product. Thus MARKK studies aesthetic phenomena — or artefacts - like advertisements, logos, brands and design. 
MARKK's interest in the formal aspects of these artefacts means: (a) that expression is favoured over content; (b) that these artefacts are treated like texts, i.e. as a coherent and defined structure of meaning (or signification). This is step 3. Because these formal aspects are analysed from a structural(istic) perspective, the focus will be on structuralistic issues like the coding of the text, the system of meaning and the formal structure of the artefact (step 4). The next step (5) informs us that MARKK is not about the meaning of these formal structures per se but about how the receiver/consumer uses the text/message and about how formal structures effect - influence or determine - the response of the receiver in the moment of exposure. In step 6, it is pointed out that effect and use is viewed as a dynamic relation - a dialectics — between cognition and culture. This intersection is made up of patterns or schemes of emotion, embodiment and thinking.

Having identified the epistemological basis of MARKK, we have also identified the consequences of the epistemological basis. The consequences thus correspond to the level of abstractness in the epistemological basis. We have listed the consequences (of the epistemological basis of MARKK) as follows:

Ad 1. The Humanities (history, analysis, interpretation, evaluation, taste)

Ad 2. A humanistic approach to Market Communication (focusing on artefacts produced to serve marketing purposes)

Ad 3. Artefacts understood as texts with focus on their formal features Ad 4. System, structure, code (paradigms/syntagms)

Ad 5. Situational aspects of effect and use

Ad 6. Schemes of emotion, embodiment and thinking

To sum up, this gives us an overall knowledge profile of MARKK (Table 1). 
Table 1. The knowledge profile of MARKK.

\begin{tabular}{|l|l|}
\hline $\begin{array}{l}\text { The epistemological basis of } \\
\text { MARKK }\end{array}$ & $\begin{array}{l}\text { The consequences of the epistemo- } \\
\text { logical basis of MARKK }\end{array}$ \\
\hline 1. Aesthetics & $\begin{array}{l}\text { Ad 1. The Humanities (history, } \\
\text { analysis, interpretation, evaluation, } \\
\text { taste) } \\
\text { Ad 2. A humanistic approach to } \\
\text { Market Communication (focusing on } \\
\text { artefacts produced to serve } \\
\text { marketing purposes) } \\
\text { 2. Aesthetics in Market } \\
\text { Communication }\end{array}$ \\
$\begin{array}{l}\text { Ad 3. Artefacts understood as texts } \\
\text { with focus on their formal features } \\
\text { in Market Communication } \\
\text { 4. Formal aspects of Aesthetics } \\
\text { in Market Communication from } \\
\text { a structuralistic perspective } \\
\text { 5. Formal aspects of Aesthetics } \\
\text { in Market Communication from } \\
\text { a structuralistic perspective with } \\
\text { focus on the process of signifi- } \\
\text { cation in the moment of exposure } \\
\text { 6. Formal aspects of Aesthetics } \\
\text { in Market Communication from } \\
\text { a structuralistic perspective with } \\
\text { focus on the process of signifi- } \\
\text { cation, understood as the inter- } \\
\text { twining of cognition and culture, } \\
\text { in the moment of exposure }\end{array}$ & $\begin{array}{l}\text { Ad } 6 . \text { Schemes of emotion, } \\
\text { anbodiment and thinking }\end{array}$ \\
\hline
\end{tabular}

As discussed earlier, the basic aim of knowledge profiling MARKK is to sharpen the use of terminology amongst the researchers within MARKK and to identify the unique fundamental sign of MARKK in order to be able to make a realistic representation of MARKK's sociocognitive knowledge organization. When focusing upon the use of terminology, the concepts are often filled with disturbing connotations that make the meaning of the concepts seem unclear not just to the members of the knowledge domain but also to people outside the knowledge domain. Naturally, this leads to misinformations and misunderstandings. Therefore, we have used the knowledge profile to 
sharpen the use of terminology in MARKK. Furthermore, we have sharpened the scientific profile of the knowledge domain. We have sharpened the terminology of MARKK to a degree where the terminology is free of disturbing connotations and where it should be beyond doubt what the focus of MARKK is. Moreover, we have identified the fundamental sign of MARKK as:

Formal aspects of Aesthetics in Market Communication from a structuralistic perspective with focus on the process of signification, which is understood as the intertwining of cognition and culture. With focus upon schemes of emotion, embodiment and thinking.

This is the fundamental sign of MARKK and it is this fundamental sign that sharpens the meaning of the concepts in use. Moreover, the fundamental sign is the basis of the conceptual structure depicted in Figure 2.

This conceptual structure is a graphic representation of key concepts in the displacement of meaning that defines the qualities inherent in the MARKK knowledge domain of. As already elaborated, MARKK is concerned with Aesthetics in Market Communication, which makes these two terms the basic related concepts.

Within the field of Humanities, aesthetics is related to the dialectics of expression and content in the signification process. As stated in the epistemological basis, MARKK's prime interest is in form favouring expression instead of content. The intended meanings or ideological values of the message are therefore in the background (and therefore grey or dim in the graphic representation). In regard to a long lasting debate within aesthetics between autonomists (stressing that aesthetics concern "a purpose without purpose" or "l'art pour l'art") and functionalists (stressing that aesthetic form should be shaped in accordance with the practical purpose of the object), MARKK favours function. This is due to MARKK's structuralistic approach. Function is analysed in terms of cognition (schemes) and culture (patterns). 


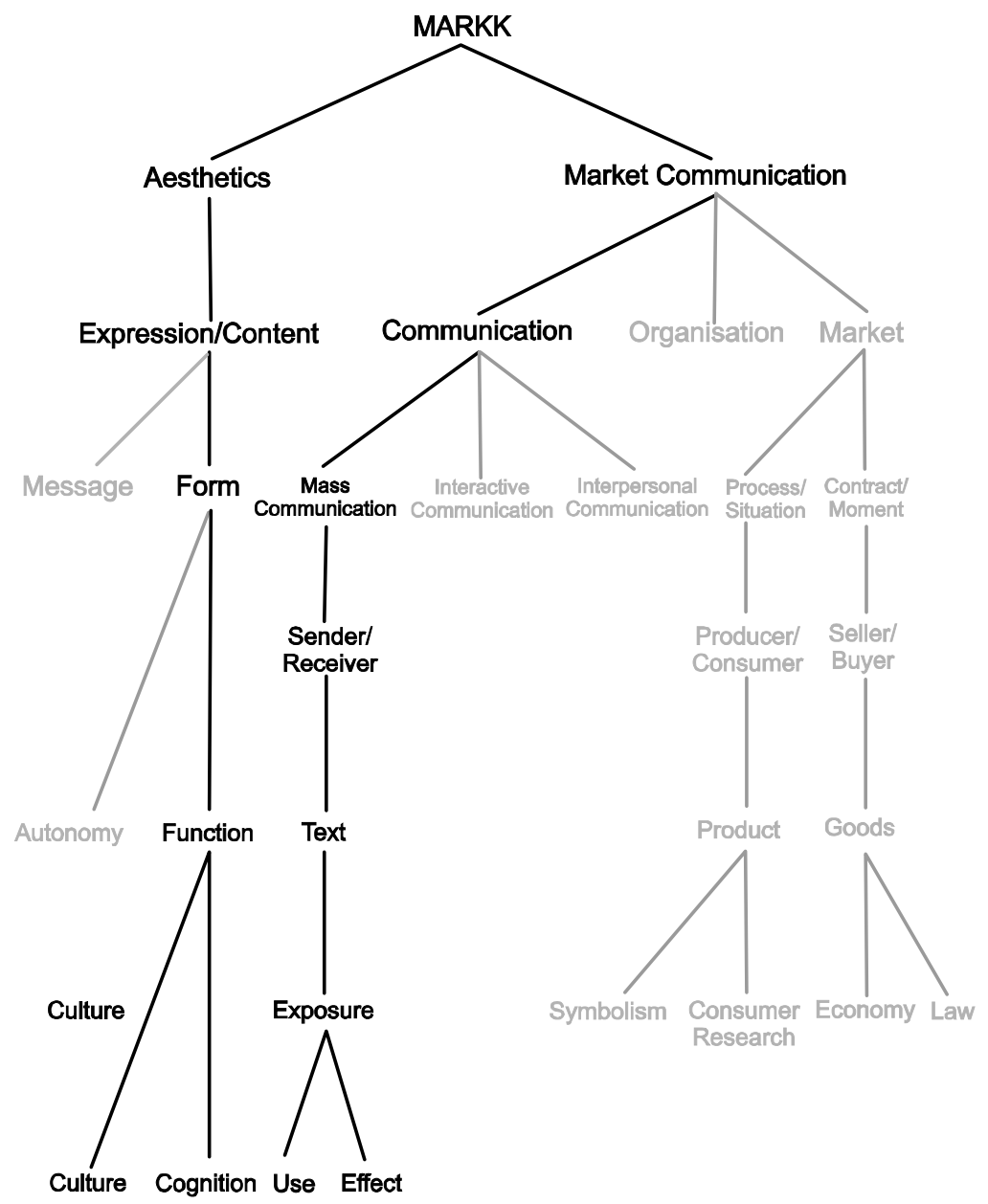

Figure 2. The knowledge map of MARKK. As pointed out in the introduction. The knowledge map is not alone built upon a top-down structure. It is a construction based upon the fundamental sign of MARKK and the consequences of this fundamental sign. This makes the knowledge map prior to any hierarchical structure and it makes knowledge mapping prior to building e.g. a thesaurus or other hierarchical structures.

The second basic concept for MARKK is Market Communication. It is a field where communication studies meet marketing, management 
(organisation studies) and other social sciences. MARKK's prime interest is in communication: i.e. the transmission and creation of meaning. In other words, as the communicative aspects of market communication are stressed, other aspects such as market and organisation are more peripheral to MARKK. Communication is a process, and MARKK's interest is on mass communication (pushing e.g. interpersonal communication into the background). The actors within mass communication are conceived as senders (active) and receivers (passive and massive). What MARKK actually analyses and investigates in this process between senders and receivers are, according to the epistemological basis, texts: aesthetic relations of expression and content in a coherent and defined structure, which serve one or more functions. In other words, texts are the manifestations of aesthetics in communication processes. These texts are analysed in respect to the ways in which they function for the receiver in the moment of exposure (or reception). These ways are pinpointed either in terms of effect or use, terms mirroring cognition and culture in the string of related concepts of aesthetics.

The graphic representation of the conceptual structure of MARKK consists of two main strings of related concepts that specify how aesthetics and market communication should be understood in a MARKK(ed) perspective. In other words, these two strings inform us on what MARKK is concerned with, the specification of aesthetics, market communication, expression/content, form, function, etc. This specification develops in a displacement of meaning that points out and defines the fundamental sign of MARKK by narrowing down the knowledge domain. The telos of the fundamental sign is realised during this process.

Moreover, this narrowing down should be understood as a continuous process of sharpening the focus of the domain, thereby shaping a more and more precise foreground. In this process, other concepts move into the background. They are not the prime focus of MARKK but, on the other hand, they are not to be discarded when dealing with the concepts in focus. They still give meaning to the strings of primary concepts. For example, the reason why market communication is a specific form of communication is the fact that the goal of the sender of market communication is to convince the receiver to buy the object of the text: that is to become a customer and a consumer. So, market communication is communication, which intends to transform receivers into buyers/customers and consumers through texts on the 
goods to be acquired (implying law and a monetary system) and the products to be appropriated (implying consumption and meaning creating acts when consuming the product).

To grasp these two different kinds of relations, the graphic representation features concepts in bold and others in grey/dim. The strings in bold represent the basic or primary conceptual structure of relations. The strings in grey represent secondary relations to the fundamental sign which, being in the background, nonetheless hold relevant information in regard to the prime concepts. The primary concepts are the relations that MARKK should constantly keep in mind. The secondary concepts are relations that MARKK should not neglect.

To summarise, the fundamental sign contains the qualities of MARKK and it is the manifestation of the interpretative habit that constrains these qualities and makes them identifiable. Consequently, the qualities of the fundamental sign are displaced from the fundamental sign to the related terms in the conceptual structure. The abstract and yet precise fundamental sign becomes the centre in the socio-cognitive structure of MARKK and the related terms become manifestations of the fundamental sign. These manifestations, e.g. aesthetics, market communication, culture, and cognition, etc. are all interpreted in relation to the fundamental sign.

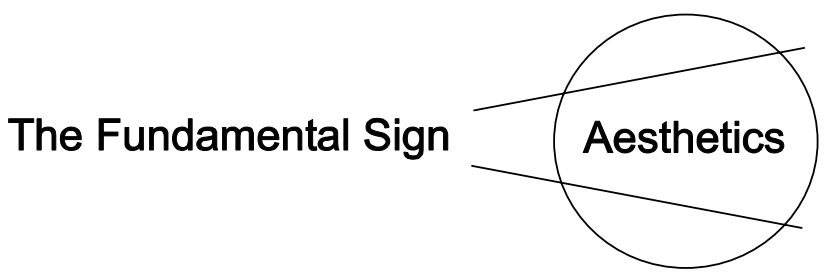

Figure 3. The fundamental sign of MARKK puts interpretative constraints upon the concepts in the conceptual structure, sharpening the meaning of aesthetics to address the purpose of MARKK.

This means that the specific MARKK-understanding of aesthetics is formed within the fundamental sign. MARKK is not about all kinds of aesthetic objects but is only interested in artefacts that fulfil purposes 
of market communication. Furthermore, MARKK is not interested in how these objects serve as works of art in their own right (industrial design as the art form of modern society or in commercials as art), or how these works have an ideological function (by glorifying values of consumerism). MARKK's focus on aesthetics is in terms of cognition (effect) and culture (use) determined by the function of the object's formal structure. In other words, the fundamental sign carves out the MARKK position in the debate on aesthetics, stressing a functionalistic and structural approach to a relatively well-defined range of aesthetic objects.

\section{What relations are?}

In the beginning of the article, we posed the following questions: What is a quality and how does a quality become displaced? What is a relation? How do relations occur? And how can we identify relations? Based on the discussions, definitions and analyses we have conducted, we are capable of answering these questions.

When identifying the fundamental sign of MARKK, we identified the epistemological qualities of MARKK. These epistemological qualities are the knowledge profile and are contained in the fundamental sign as epistemological constraints. The epistemological qualities of a concept are the epistemological features of the concept stemming from the goals of the particular knowledge domain. The epistemological qualities of MARKK are unique; hence the knowledge organisation is also unique. Since the fundamental sign puts constraints upon all the related terms, the epistemological qualities from the fundamental sign are displaced into the related terms. In the case of MARKK, it is important to understand the significance of the fundamental sign. If we have no knowledge about the fundamental sign in e.g. MARKK, we will not be able to understand the meaning of the related terms in the way the knowledge domain wants us to. This is what we try to stress in Figure 3 when showing that the fundamental sign puts constraints upon aesthetics. It is aesthetics in the way MARKK understand aesthetics that is interesting for us to know. The outcome is that the meaning of every related term in the knowledge map (Figure 2) have to be understood in relation to the fundamental sign, again this means that the epistemological qualities of the fundamental sign have been displaced to the related terms and 
the displacement constrains the related terms with epistemological constraints.

In order to answer how an epistemological quality becomes displaced, we must answer the question posted above regarding related terms.

We understand relations as consequences. To become related terms, consequences have to be tested through the use and experience of the researchers within a given knowledge domain. If the consequence fails the test, it may wither away. Positively tested consequences become general relations and general relations are related terms and only general relations can be related terms. In the case of MARKK, there are three clear indications of a positive testing, besides the fact that the graphic representation of conceptual structure has been drafted by the MARKK members in their work with the knowledge profile:

(1) the interrelatedness between the two primary strings in regard to the concepts of text, function, reception, etc.;

(2) the interrelatedness between primary and secondary concepts: e.g. sender/receiver, seller/buyer, producer/consumer, illustrating the intricacies of market communication as well as pin pointing the main focus of MARKK;

(3) the mirroring of concepts at the end of each string: effect implying cognition; use implying culture.

The answer to how relations occur is embedded in the above. A consequence occurs whenever a concept is interpreted. The consequence is a manifestation of the knowledge potential of a concept in accordance with the knowledge domain from which the concept originates.

How may we then identify relations? Since it is the knowledge domain that constructs the scientific context where the terminology is developed, we argue that every concept within this socio-cognitive structure in fact is a related term. As a starting point, only one concept exists in the knowledge domain and this concept is the fundamental sign. The fundamental sign contains the epistemological qualities of the knowledge domain and it is the displacement of these epistemological qualities that creates and constrains the related terms.

If we look at Figure 3, we see how the fundamental sign sharpens and forms the meaning of aesthetics by reducing the knowledge potential of aesthetics to match the knowledge need of MARKK in providing aesthetics with the telos of the fundamental sign. In this way, the epistemological qualities of the fundamental sign, the goal of 
MARKK has been displaced to the related term and the meaning of aesthetics within the context of MARKK is unique to this knowledge domain. This makes the fundamental sign of MARKK equivalent to the interpretative habit discussed earlier in the article.

To get deeper into the understanding of the displacement of meaning, let us return to the concept pragmaticistic constructivism. As discussed above, Figure 3 shows how meaning becomes displaced from the fundamental sign to the related term. When drawing the knowledge profile, we sharpen and construct the meaning of MARKK embedded in the fundamental sign. Each time we sharpen the epistemological basis, we make a choice that ultimately could have been different with different consequences. Essentially, this means that we construct the telos for MARKK as we construct the fundamental sign. The meaning of the related terms is partly created by the fundamental sign through displacement of meaning (epistemological qualities and the interpretative habit in form of a telos) and partly by the epistemological qualities contained within the concept (which becomes the related term). Aesthetics is an abstract concept containing a vast knowledge potential. However, when it becomes constrained by the fundamental sign of MARKK, it becomes a related term that match the knowledge need of MARKK, which essentially contained both the epistemological qualities of the fundamental sign of MARKK and its general qualities that defined aesthetics as an abstract concept. However, the displacement of epistemological qualities implants the telos of MARKK in aesthetics, constructing the meaning of aesthetics to match the knowledge need of MARKK. These processes are displacements of epistemological qualities and implantations of telos'. Seen as a whole, these processes are pragmaticistic constructivism.

\section{Conclusion}

We have introduced a new and hopefully better way to make realistic representations of knowledge organizations based on an intellectual method called the knowledge profile. We have defined the knowledge profile and we have profiled the knowledge domain of MARKK. Using Peirce's doctrine of pragmaticism, we have been able to answer the questions regarding relations. We have defined the nature of related terms and we have argued that a related term is a result of usability tests in the knowledge domain. We have shown how to 
identify related terms based on the displacement of epistemological qualities from the fundamental sign to the related terms. We have also argued that the fundamental sign is the identifiable interpretative habit of the knowledge domain that constrains the related terms to contain a certain meaning. Indeed, we believe that the knowledge profile is the answer to the search for methods of making representations of knowledge organisations based on pragmatic semiotics, which researchers have been aiming at over the last decade.

\section{References}

Hausman, Carl R. 1993 Charles S. Peirce's Evolutionary Philosophy. Cambridge: Cambridge University Press.

Peirce, Charles. S. 1931-1966. Collected Papers of Charles Sanders Peirce, 8 vols., ed. by Charles Hartshorne, Paul Weiss, and A. W. Burks. Cambridge: Harvard University Press.

Thellefsen, Torkild 2002. Semiotic knowledge organization: Theory and method development. Semiotica 142: 71-90.

- 2003a. Pragmaticism and the role of terminology. Impact [an electronic journal, www.impact.hum.auc.dk].

- 2003b. Semiotics of terminology: A semiotic knowledge profile. SEED Journal 3(2) [an electronic journal, www.library.utoronto.ca/see/pages/SEED_Journal.html

- 2004a. The fundamental sign. Semiotica (forthcoming).

- 2004b. Knowledge profiling: The basis for knowledge organization. Library Trends (forthcoming).

Thellefsen, Torkild; Brier, Søren; Thellefsen, Martin 2003. Indexing and significance-effect: A Peircian semiotic and cognitive semantic approach to the analysis of the problems of subject searching. Semiotica 144: 177-218.

\section{Чем являются отношения: \\ изучение концептуальных связей, сдвиг значения и профилирование знания}

Цель статьи - ознакомить с профилем знания как средством дать реалистическое представление об организации знания. Для репрезентации такого реалистического знания мы должны сначала идентифицировать основной, фундаментальный знак данной области знания, хотя может показаться, что основной знак приведет к эпистемологическому “насилию” над изучаемыми объектами, создавая в конечном итоге организацию знания только одной уникальной 
области знания. Далее в статье указывается на то, что если мы хотим дать реалистическое представление об организации знания, мы должны знать, каким образом концептуальные связи проявляются, развиваются и становятся соотнесенными терминами. Чтобы подкрепить свои теоретические утверждения и показать пригодность профиля знания, мы включаем пример изучения одной конкретной области знания.

\section{Mis on suhted: \\ kontseptuaalsete suhete uuring, tähenduse nihe ja teadmise profileering}

Artikli eesmärk on tutvustada teadmise profiili kui vahendit anda tõepärane esitus teadmise korraldusest. Tõepärase teadmise esitamise puhul peame me kõigepealt identifitseerima antud teadmisvaldkonna baasmärgi, kuid sel juhul näib, et baasmärk sätestab epistomoloogiliste sunduste prioriteedi uuritavate objektide suhtes, andes lõpptulemusena ühe, ainukordse teadmisvalla teadmise korralduse. Edaspidi juhitakse tähelepanu faktile, et kui me soovime anda teadmise korralduse tõepärast esitust, peame me teadma, mil viisil kontseptuaalsed suhted ilmuvad, arenevad ja saavad suhestatud terminiteks. Põhjendamaks oma teoreetilisi väiteid ja näitamaks teadmisprofiili kasutamiskõlblikkust, lisame ka ühe konkreetse teadmisvalla uuringu. 